\title{
Sodium and Water Balance in Chronic Congestive Heart Failure
}

\author{
Robert J. Cody, Andrew B. Covit, Gary L. Schaer, John H. Laragh, Jean E. Sealey, and Joseph Feldschuh \\ Cardiology Division and Hypertension Center, New York Hospital/Cornell University Medical College, New York, New York 10021
}

\begin{abstract}
As the characteristics of sodium and water balance in heart failure remain undefined, we evaluated the hemodynamic, metabolic, and hormonal effects of balanced sodium intake in 10 patients with chronic congestive heart failure. We discontinued diuretics to avoid their confounding influence, and all patients received 1 wk of $10 \mathrm{meq}$ and $100 \mathrm{meq}$ balanced sodium intake and controlled free water. Comparing sodium intake of 10 with 100 meq, the following observations were made. There was weight gain (2.0 $\mathrm{kg})$ and increased sodium excretion (11 \pm 3 to $63 \pm 15 \mathrm{meq} / 24 \mathrm{~h})$, unaccompanied by increase of blood volume. Both renin-angiotensin system and sympathetic nervous system activity were greater during the 10 meq diet, and suppressed with the 100 meq sodium diet. For both diets, plasma renin and urinary aldosterone excretion were correlated with urinary sodium excretion $(r=-0.768, r=-0.726$, respectively; $P<0.005)$. Systemic hemodynamics were minimally changed with increased sodium intake. However, reversal of vasoconstriction by captopril during the 10 meq diet, and its ineffectiveness during the 100 meq diet, indicated a renin-dependent mechanism in the former, and a renin-independent mechanism in the latter diet. There were two subgroups of response to the 100 meq diet: one group $(n=5)$ achieved neutral balance, while the second $(n=5)$ avidly retained sodium and water. Renin-angiotensin system activity was significantly higher in the latter group, and the mechanism for differences in sodium excretion for the subgroups could not be identified by blood volume or hemodynamic parameters. Orthostatic hypotension during tilt was greater during the 10 meq sodium diet, and in all cases, related to ineffective hemodynamic and hormonal compensatory responses.
\end{abstract}

\section{Introduction}

The pathophysiology of sodium and water retention remains one of the most poorly defined aspects of chronic congestive heart failure. A fundamental problem is the lack of adequate characterization of dietary sodium intake on the hemodynamic, hormonal, and metabolic characteristics of congestive heart failure. Previous studies have often resulted in inexplicable findings regarding sodium and water retention. For instance, Ayers and coworkers have shown that sodium retention can be virtually complete, despite a relatively normal aldosterone secretory rate

Address correspondence to Dr. Cody, Cardiology Division, New York Hospital/Cornell University Medical College, 525 East 68th Street, New York, NY 10021.

Received for publication 10 April 1985 and in revised form 21 November 1985.

J. Clin. Invest.

(c) The American Society for Clinical Investigation, Inc.

0021-9738/86/05/1441/12 \$1.00

Volume 77, May 1986, 1441-1452
(1). Chonko and co-workers identified two responses to sodium loading in heart failure (2). One was associated with persistent activation of the renin angiotensin system, while the second group retained sodium despite suppression of the renin angiotensin system. These studies were limited, in that the response to only high sodium intake was characterized, and hemodynamic measurements were not obtained. Furthermore, there are no data regarding the relationship of dietary sodium intake to interruption of the renin angiotensin system, which is an important determinant of vasoconstriction and sodium retention in heart failure. The major limitation of many present clinical studies of congestive heart failure is that patients are evaluated while receiving diuretic therapy, or within a few days of discontinuation of diuretics, so that an adequate dietary sodium baseline is not established. Diuretic therapy not only alters the renal handling of sodium and water, but it can also distort the basal level of neurohormonal factors that regulate sodium and water retention, such as the renin angiotensin system (3-5). A recent editorial (6) has reiterated the need for controlled studies that assess the factors regulating sodium and water regulation in chronic congestive heart failure, to more clearly differentiate pathophysiologic mechanisms from factors that may be epiphenomena. Therefore, the present study has evaluated the metabolic, hormonal, and hemodynamic characteristics of sodium and water regulation during balanced sodium intake in untreated patients with moderate to severe chronic congestive heart failure.

\section{Methods}

Patient population. The study consisted of 10 consecutive patients with moderate to severe chronic congestive heart failure, referred for diagnostic evaluation and treatment. All patients gave written informed consent prior to participation in this study, which was approved by the Committee on Human Rights in Research. There were eight male and two female patients ranging in age from 43 to 72 yr. Subjectively, all patients enrolled in this study gave a longstanding history of congestive heart failure that included one or more of the following symptoms: dyspnea on exertion, paroxysmal nocturnal dyspnea, ankle swelling, and effort-related fatigue. Objectively, chronic left ventricular dysfunction and dilatation were documented by cardiac catheterization, echocardiography, or radionuclide cineangiography. All patients had evidence of cardiomegaly on chest $x$-ray with a cardiothoracic ratio greater than $55 \%$. All patients were previously treated with a digitalis preparation and a diuretic, and many of the patients were previously treated with one or more vasodilator regimens. The etiology of congestive heart failure was ischemic in four patients and nonischemic in six patients. Patients with hypertension, valvular heart disease, myocardial infarction within the previous 6 mo, and patients with recent acute decompensation were excluded from this study. In addition to the 10 patients who successfully completed the protocol, an additional four patients were originally enrolled but subsequently excluded from the protocol and/or final analysis. This included one patient who developed low output symptoms upon discontinuation of his previous medications, one patient who developed accelerated progression of symptoms during the high sodium diet and two patients who were not in compliance with dietary sodium manipulation.

Overall protocol design. The overall design of the protocol is shown in Fig. 1. All diuretics and vasodilator therapy were tapered and discon- 


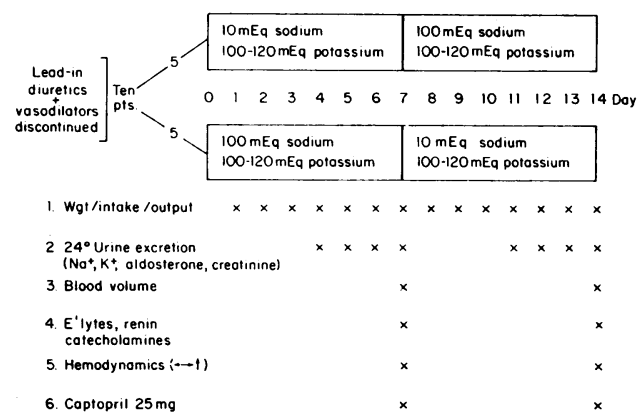

Figure 1. Overall protocol for the assessment of sodium and water balance in chronic congestive heart failure. All 10 patients received both the $10 \mathrm{meq}$ and $100 \mathrm{meq}$ sodium diets. Hemodynamic measurements were obtained in the supine $(\leftrightarrow)$ and upright $(\uparrow)$ positions, both before and after a $25-\mathrm{mg}$ oral dose of the converting enzyme inhibitor, captopril.

tinued for 3-7 d prior to enrollment in this study. In addition, digitalis preparations were discontinued in all but three patients, the latter requiring digoxin for control of ventricular response in the presence of atrial fibrillation. Patients were admitted to the adult Clinical Research Center of New York Hospital/Cornell University Medical College. This is a metabolic unit, with two full time dieticians who controlled the menu and sodium intake for the patients. All food was prepared in the metabolic kitchen of the Clinical Research Center. Research nursing personnel ensured accurate assessment of daily weights, total intake and output, and the timing and completion of all 24-h urine collections. All 10 patients received both a balanced low sodium diet $(10 \mathrm{meq})$ and a moderate sodium diet (100 meq). Each diet also contained 60-80 meq of potassium, which was supplemented by $40 \mathrm{meq}$ of oral potassium chloride elixir. Once the diet had been chosen for the individual patients, the same menu was prepared for each of the three meals throughout the course of the study. The diet was isocaloric, and total daily fluid intake was strictly controlled at $2,000 \mathrm{ml}$ daily. To minimize any bias regarding the sequence of diet, or the influence of duration of hospital stay on any hemodynamic or metabolic parameters for a given diet, 5 of the 10 patients were randomized to either the 10 meq sodium or $100 \mathrm{meq}$ sodium diet as their first diet. Patient menus were structured so that the daily food intake contained approximately $10 \mathrm{meq}$ sodium. The difference between $10 \mathrm{meq}$ and 100 meq sodium was achieved by administration of sodium chloride tablets with each of the meals. The actual amount of sodium consumed on the higher sodium intake, as independently estimated by the dietary staff, was $\sim 86-146$ meq. On the first day of the 10 meq sodium diet, all patients received a single oral dose of furosemide $(1 \mathrm{mg} / \mathrm{kg})$, to initiate natriuresis. All patients were weighed daily in the morning prior to breakfast. An accurate daily record was kept of fluid, sodium, potassium, and caloric intake. Likewise, daily 24$\mathrm{h}$ urine collections were obtained beginning at 8:00 a.m. and closing at 8:00 a.m. of the following morning. To ensure that sodium balance was being achieved, four 24-h urine collections were analyzed for volume, sodium, potassium, and aldosterone excretion at the end of each dietary period. In addition, creatinine clearance was calculated from the urine collections. For analysis in this study, the 24-h urine collection which closed on the morning of the hemodynamic study (the last day of each diet) was used for all analyses and comparisons. On the last day of each diet, patients underwent hemodynamic study.

Hemodynamic study was performed early in the morning following overnight fast, in all patients. A right heart catheter was placed percutaneously from either an antecubital vein, or an internal jugular vein. A cannula was also placed in the radial artery of all patients. Details of these procedures are as previously described (7). Following catheter placement, a 1-h stabilization period ensued. Baseline measurements were then obtained. This consisted of hemodynamic recordings, determination of total blood volume, and blood samples for serum chemistries, plasma renin activity, and plasma norepinephrine. Once supine measurements were obtained, we then assessed the hemodynamic and neurohormonal autoregulatory response to the gravitational stress of head up tilt as previously described $(7,8)$. Tilt was performed in order to assess the impact of dietary sodium manipulation on compensatory hemodynamic autoregulation of blood pressure, and mechanoreceptor stimulation of renin and norepinephrine. All hemodynamic studies were performed on an electronic tilt table. Upright hemodynamics were obtained by tilting the patient to 60 degrees for $15 \mathrm{~min}$. Pressure transducers were attached to the table, and positioned midway between the anterior and posterior chest wall. The transducers were affixed to a swivel mount, maintaining the same relative level in relation to the atria, so that the phlebostatic level of Rushmer (9) was maintained for accurate pressure measurements during tilt. Orthostatic hypotension was defined as a decrease of mean arterial pressure in excess of $10 \%$, compared to supine values. Following head up tilt, all patients were returned to the supine position for a reequilibration period of at least $30 \mathrm{~min}$. All patients then received a $25 \mathrm{mg}$ oral dose of captopril as a pharmacologic inhibitor of the renin angiotensin system (10). The hemodynamic response to captopril was followed to peak effect which occurred at $60-90 \mathrm{~min}$ in all patients, corresponding with the previously described peak hemodynamic and pharmacokinetic time course of captopril (11). Hemodynamic recordings and blood samples for plasma renin activity and norepinephrine were obtained at supine peak effect. Patients then underwent repeat head up tilt with recording of hemodynamic indices and blood samples for plasma renin activity and plasma norepinephrine. The total amount of blood sampled during each hemodynamic study was approximately 90 $\mathrm{ml}$. The hemodynamic data obtained throughout the study consisted of continuous recording of heart rate (beats per minute), right atrial pressure $(\mathrm{mm} \mathrm{Hg})$, pulmonary artery pressure $(\mathrm{mm} \mathrm{Hg})$, intermittent pulmonary capillary wedge pressure $(\mathrm{mm} \mathrm{Hg}$ ), and systemic arterial pressure $(\mathrm{mm}$ $\mathrm{Hg}$ ). Cardiac output was determined by the thermodilution technique with determinations made in triplicate. Blood pressures were recorded as phasic and electronically dampened mean and for the purposes of this study, all blood pressures are expressed as the mean values. Derived hemodynamic values were by standard formulae (12). This consisted of cardiac index (liters/minute per meter ${ }^{2}$ ), stroke volume index (milliliters/ meter $\left.{ }^{2}\right)$, systemic vascular resistance $\left(\right.$ dyn $\left.\cdot \mathrm{s} \cdot \mathrm{cm}^{-5}\right)$, and pulmonary vascular resistance $\left(\right.$ dyn $\left.\cdot \mathrm{s} \cdot \mathrm{cm}^{-5}\right)$.

Neutral sodium balance vs. sodium retention. Five patients achieved neutral sodium balance, while five patients continued to avidly retain sodium, following 1 wk of the 100 meq sodium diet. The characteristics for these two subgroups are given in Table I. In addition, the individual patients for these two subgroups are identified in Figs. 2, 3, and in Fig. 7 (see Appendix) by different symbols. Patients in neutral sodium balance are identified by open circles representing the 10 meq sodium diet, and closed circles representing the 100 meq sodium diet. Patients retaining sodium are identified by open triangles ( $10 \mathrm{meq}$ sodium diet), and closed triangles (100 meq sodium diet).

Analysis of blood and urine collections. Blood samples were analyzed for serum sodium (mmol/liter), serum potassium (mmol/liter), serum chloride ( $\mathrm{mmol} / \mathrm{l}$ ), serum bicarbonate (mmol/liter), blood urea nitrogen $(\mathrm{mg} / \mathrm{dl})$, and serum creatinine $(\mathrm{mg} / \mathrm{dl})$. All hormonal samples were obtained in the supine fasting state, or where noted, during head-up tilt. Plasma renin activity was determined by radioimmunoassay of generated angiotensin I as previously described by our laboratory (13). Plasma norepinephrine was determined by radioenzymatic assay (14). Plasma volume was estimated, using the radioiodinated albumin $\left(\mathrm{I}^{131}\right)$ technique as previously described (15). Plasma volume was corrected for the hematocrit, to approximate total blood volume which was expressed in milliliters, and also as percent of the predicted normal.

Following determination of 24-h urine volumes, sodium and potassium excretion were determined by flame photometric techniques, and expressed as meq/24 h. Creatinine excretion was determined by standard techniques, with calculation of creatinine clearance expressed as $\mathrm{ml} /$ min. Urinary aldosterone excretion was determined by radioimmunoassay as previously described by our laboratory (16), and expressed as micrograms $/ 24 \mathrm{~h}$. 
Table I. Characteristics of Sodium Handling during 100-meq Sodium Diet

\begin{tabular}{|c|c|c|c|c|c|c|c|c|c|c|c|c|c|c|}
\hline & \multicolumn{2}{|l|}{ Sodium } & \multicolumn{2}{|l|}{ Water } & \multirow[b]{2}{*}{ PV } & \multirow[b]{2}{*}{ BV } & \multirow[b]{2}{*}{$\mathrm{C}_{\mathrm{a}}$} & \multirow[b]{2}{*}{ BUN } & \multirow[b]{2}{*}{ PRA } & \multirow[b]{2}{*}{ Ualdo } & \multirow[b]{2}{*}{ MAP } & \multirow[b]{2}{*}{ PCWP } & \multirow[b]{2}{*}{$\mathrm{CI}$} & \multirow[b]{2}{*}{ SVR } \\
\hline & Intake & Excretion & Intake & Excretion & & & & & & & & & & \\
\hline & meq & meq & $m l$ & $m l$ & $m l$ & $m l$ & $\mathrm{ml} / \mathrm{min}$ & $m g / d l$ & $n g / m l$ per $h$ & $\mu g / 24 h$ & $m m \mathrm{Hg}$ & $\mathrm{mm} \mathrm{Hg}$ & liters $/$ min per $M^{2}$ & dyne $\cdot \mathrm{s} \cdot \mathrm{cm}^{-\mathrm{s}}$ \\
\hline \multicolumn{15}{|c|}{$\begin{array}{l}\text { Neutral sodium } \\
\text { balance }\end{array}$} \\
\hline \multirow[t]{5}{*}{$(n=5)$} & 140 & 141 & 2,080 & 2,010 & 3,617 & 6,057 & 91 & 10 & 0.64 & 8.0 & 94 & 24 & 2.49 & 1,272 \\
\hline & 113 & 92 & 2,860 & 1,860 & 4,219 & 6,973 & 104 & 12 & 0.48 & 13 & 80 & 24 & 2.26 & 1,136 \\
\hline & 112 & 106 & 2,360 & 1,855 & 3,095 & 5,527 & 89 & 11 & 0.14 & 4.7 & 117 & 18 & 2.46 & 1,880 \\
\hline & 86 & 82 & 2,290 & 1,880 & 3,686 & 5,265 & 62 & 14 & 0.24 & 3.0 & 82 & 24 & 2.30 & 1,376 \\
\hline & 107 & 91 & 1,300 & 1,650 & 1,937 & 2,935 & 75 & 14 & 0.48 & 3.5 & 98 & 19 & 1.93 & 2,314 \\
\hline Mean & 114 & 102 & 2,178 & 1,851 & 3,311 & 5,351 & 84 & 12 & 0.4 & 6.4 & 94 & 22 & 2.29 & 1,595 \\
\hline SEM & 9 & 10 & 254 & 58 & 274 & 671 & 8 & 1 & 0.1 & 1.9 & 7 & 1 & 0.10 & 219 \\
\hline \multicolumn{15}{|c|}{ Sodium retaining } \\
\hline \multirow[t]{5}{*}{$(n=5)$} & 111 & 2 & 1,825 & 690 & 3,343 & 5,223 & 46 & 18 & 1.8 & 20 & 88 & 22 & 1.92 & 1,648 \\
\hline & 146 & 21 & 2,660 & 530 & 3,069 & 5,580 & 96 & 16 & 1.6 & 12 & 80 & 27 & 2.25 & 1,344 \\
\hline & 112 & 7 & 1,305 & 620 & 2,637 & 4,186 & 47 & 34 & 2.5 & 20 & 70 & 22 & 2.32 & 1,328 \\
\hline & 112 & 56 & 1,875 & 770 & 2,730 & 4,550 & 69 & 16 & 0.57 & 9.4 & 94 & 34 & 1.51 & 2,552 \\
\hline & 107 & 35 & 1,500 & 780 & 3,757 & 6,591 & 138 & 16 & 2.5 & 9.7 & 81 & 23 & 1.75 & 1,560 \\
\hline Mean & 117 & 24 & 1,833 & 678 & 3,107 & 5,227 & 79 & 20 & 1.8 & 14 & 83 & 26 & 1.99 & 1,625 \\
\hline SEM & 7 & 10 & 232 & 47 & 145 & 542 & 17 & 4 & 0.4 & 2.4 & 4 & 2 & 0.13 & 166 \\
\hline$P^{*}$ & NS & .001 & NS & 0.001 & NS & NS & NS & 0.05 & 0.005 & 0.03 & NS & NS & NS & NS \\
\hline
\end{tabular}

* Significance of the difference between neutral sodium and sodium-retaining subgroups.

Statistical analysis. Comparison of baseline metabolic parameters for each of the two sodium intakes was assessed by Student's paired $t$ test. Linear regression was used for analysis of metabolic data using a $\log$ transformation for curvilinear relationships. Due to the wide range of values of plasma renin and norepinephrine, log transformation of

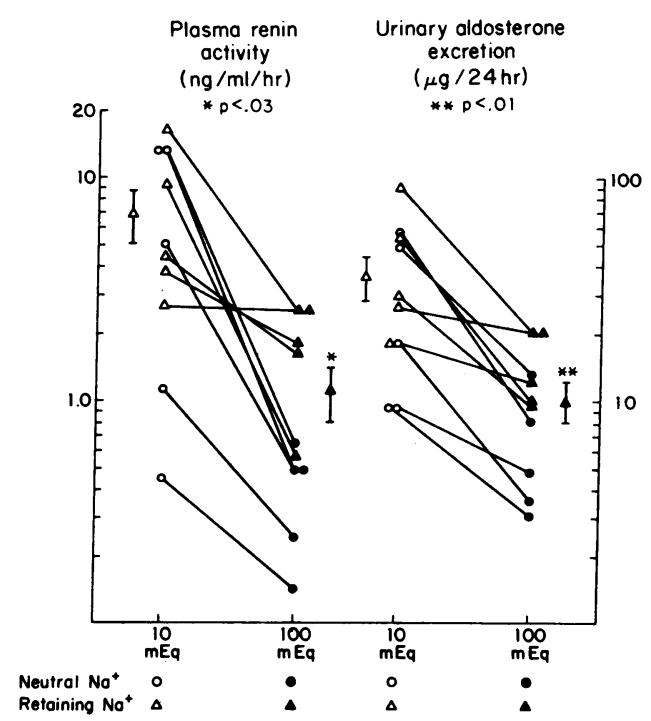

Figure 2. Supine plasma renin activity, and 24-h urinary aldosterone excretion for the two sodium diets. The circles represent those patients who ultimately achieved neutral sodium balance on the $100 \mathrm{meq}$ sodium diet, while the triangles represent those patients who continued to retain sodium during the 100 meq sodium diet. Sodium repletion with 100 meq resulted in suppression of both plasma renin activity and urinary aldosterone secretion. However, the greatest suppression of the renin-angiotensin system during the 100 meq sodium diet was achieved in those patients who were in neutral sodium balance (closed circles). Mean values are given, \pm 1 SEM. these parameters was performed prior to statistical analysis. The hemodynamic and hormonal profile of these patients was subject to three independent variables. These were sodium intake, inhibition of the renin angiotensin system by captopril, and position. We performed a two-way analysis of variance to determine the influence of these three factors, as well as the possibility of an interaction among the three factors $(17,18)$. This tested the significant influence of sodium intake (10 vs. $100 \mathrm{meq}$ ), inhibition of the renin angiotensin system (pre- and post-captopril), and position (supine vs. tilt). The mean values for the two-way analysis of variance are given in Figs. 4 and 5 , and the individual patient data are given in the Appendix (Fig. 7). Differences were considered statistically significant if they achieved a $P$ value of 0.05 . All values are expressed as mean \pm SEM.

\section{Results}

Hemodynamic profile during balanced sodium intake. The influence of dietary sodium on the hemodynamic profile of the patients in this study is summarized in Table II. The resting hemodynamic parameters indicate moderate to severe congestive heart failure: a reduction of cardiac index and stroke volume index to approximately $60 \%$ of normal, an increase of right and left ventricular filling pressures, and an increase of both systemic and pulmonary vascular resistance. Comparison of the $10 \mathrm{meq}$ sodium to the 100 meq sodium diet revealed that mean arterial pressure increased from $83 \pm 3$ to $88 \pm 4 \mathrm{~mm} \mathrm{Hg}$, pulmonary artery pressure increased from $27 \pm 4$ to $36 \pm 3 \mathrm{~mm} \mathrm{Hg}$, and pulmonary capillary wedge pressure increased from $16 \pm 3$ to $24 \pm 1 \mathrm{~mm} \mathrm{Hg}$ (all $P<0.02$ ). However, forward flow (cardiac index and stroke volume index), system, and pulmonary resistance were not significantly altered by dietary sodium.

Metabolic response to balanced sodium intake. The metabolic response to balanced sodium intake is shown in Table III. There was a 2-kg weight difference, comparing the $10 \mathrm{meq}$ to the 100 meq sodium intake $(P<0.05)$. However, this weight difference was not manifest by changes in plasma volume or total blood 

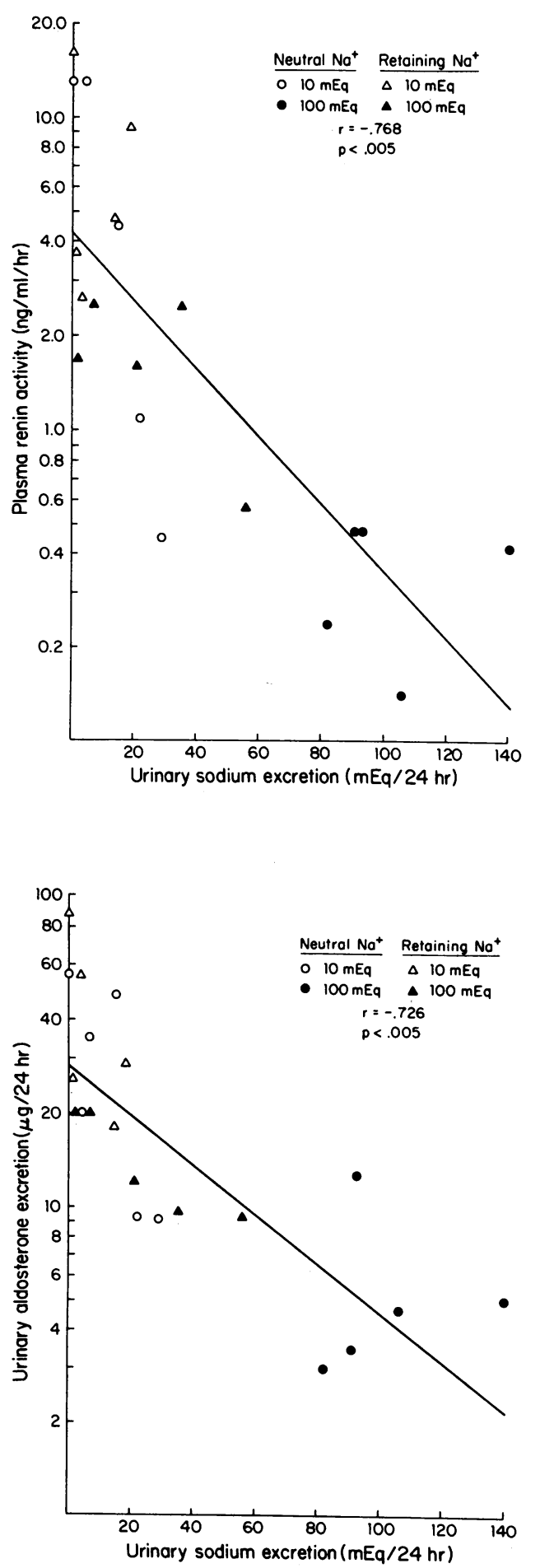

Figure 3. The correlation of plasma renin activity and urinary aldosterone excretion with 24-h urinary sodium excretion. Both plasma renin and urinary aldosterone are expressed on a logarithmic scale, and the regression coefficient is based on the logarithmic transformation of these values. Individual patients are identified, according to their ultimate response to the 100 meq sodium diet. Those who achieved neutral sodium balance are represented by circles, while those who retained sodium are indicated by triangles. The greatest suppression of the renin-angiotensin system occurred in those individuals who achieved neutral balance during the 100 meq sodium diet (closed circles).

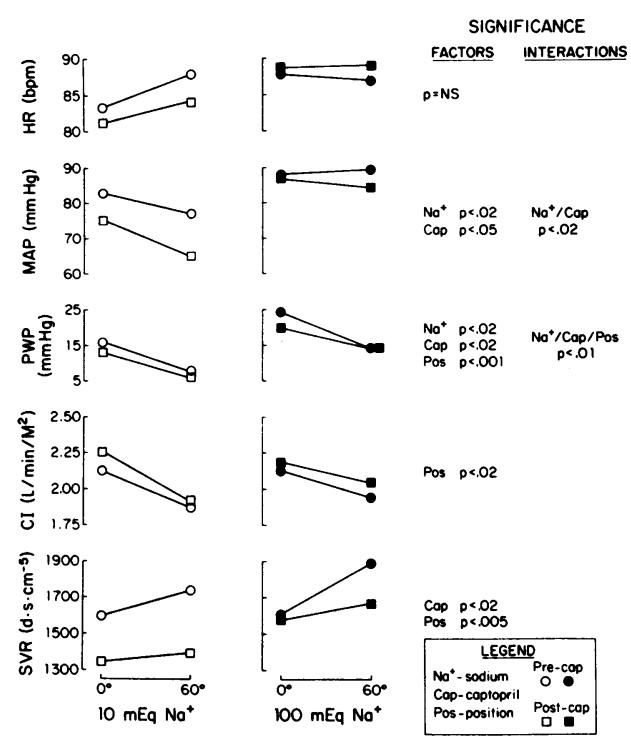

Figure 4. The hemodynamic characteristics of patients with congestive heart failure during dietary sodium manipulation. The characteristics during the 10 meq sodium diet are shown in the left panel, and the characteristics during the 100 meq sodium diet are shown in the right panel. All parameters were measured in the untreated state $(10 \mathrm{meq}$, open circles; $100 \mathrm{meq}$, closed circles), and after converting enzyme inhibition with captopril (10 meq sodium, open squares; 100 meq sodium, closed squares). To determine the influence of dietary sodium manipulation and blockade of the renin-angiotensin system on postural hemodynamics, all hemodynamic parameters before and after converting enzyme inhibition were assessed in the supine position (zero ${ }^{\circ}$ ) and during head-up tilt $\left(60^{\circ}\right)$. The significance of the three individual factors-dietary sodium intake $(\mathrm{Na}+)$, converting enzyme inhibition with captopril (Cap), and the influence of body position (Pos)-are given under the column heading of "Factors." In the column with the heading "Interactions" are listed the significant interactions between two or more of these individual factors. The values shown represent the mean values at all points for the group of $10 \mathrm{pa}$ tients. The mean values \pm 1 SEM are given in the text, and individual patient values as well as mean values are also shown in Fig. 7.

volume. During the 10 meq sodium diet, plasma volume was $3,025 \pm 242 \mathrm{ml}$, and total blood volume was $5,062 \pm 430 \mathrm{ml}$. During the 100 meq sodium diet, there was a slight but insignificant increase of both plasma volume to $3,209 \pm 209 \mathrm{ml}$, and total blood volume to $5,296 \pm 418 \mathrm{ml}$. Creatinine clearance was $81 \pm 8$ $\mathrm{ml} / \mathrm{min}$ during the $10 \mathrm{meq}$ sodium diet and $82 \pm 9 \mathrm{ml} / \mathrm{min}$ during the 100 meq sodium diet, reflecting a mild to moderate decrease in renal function for the patients as a group, but without significant alteration during dietary sodium manipulation. Sodium intake reflected the dietary manipulation and the differences were statistically significant $(P<0.001)$. The difference in dietary sodium intake was also apparent in urinary sodium excretion ( $11 \pm 3$ vs. $63 \pm 15 \mathrm{meq} / 24 \mathrm{~h}, P<0.001$ ). For both diets, urinary potassium excretion and water excretion reflected dietary intake, and there were no significant differences when the two diets were compared. Plasma norepinephrine was $519 \pm 54 \mathrm{pg} / \mathrm{ml}$ for the $10 \mathrm{meq}$ sodium intake, and $455 \pm 69 \mathrm{pg} / \mathrm{ml}$ during the $100 \mathrm{meq}$ sodium intake $(P<0.01)$. Blood chemistries are summarized in Table III and did not demonstrate significant differences when the two diets were compared. Of note, the metabolic abnor- 

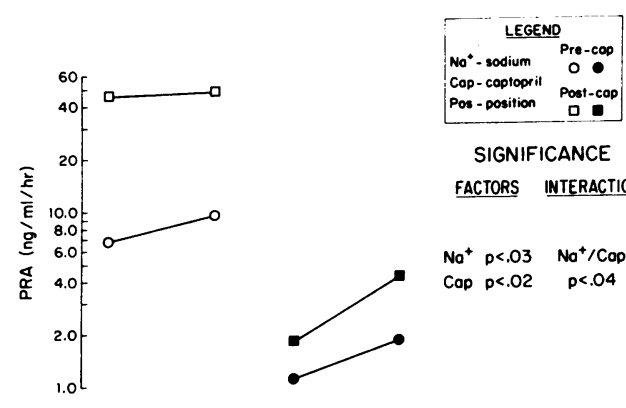

SIGNIFICANCE

FACTORS INTERACTION

$\mathrm{No}^{+} \mathrm{p}<.03 \quad \mathrm{Na}^{+} / \mathrm{Cop}$

Cap $p<.02 \quad p<.04$
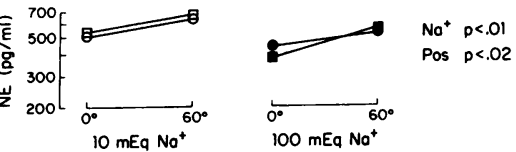

Figure 5. The influence of dietary sodium intake, converting enzyme inhibition, and posture on plasma renin activity and plasma norepinephrine. The symbols and format are as given for Fig. 4 .

malities usually seen in congestive heart failure during diuretic therapy, notably, hyponatremia, hypokalemia, and contraction alkalosis, were not observed in this study.

Dietary sodium and renin angiotensin system activity. Dietary sodium manipulation resulted in significant alteration of the extent to which the renin-angiotensin system was activated (Fig. 2 ). During the $10 \mathrm{meq}$ sodium diet, plasma renin activity was $6.8 \pm 1.8 \mathrm{ng} / \mathrm{ml}$ per $\mathrm{h}$, and urinary aldosterone excretion was $34 \pm 6$ $\mu \mathrm{g} / 24 \mathrm{~h}$. During the $100 \mathrm{meq}$ sodium diet, there was suppression of plasma renin to $1.1 \pm 0.3 \mathrm{ng} / \mathrm{ml}$ per $\mathrm{h}(P<0.02)$, and urinary aldosterone excretion to $10 \pm 2 \mu \mathrm{g} / 24 \mathrm{~h}(P<0.01)$. The correlation of plasma renin activity with urinary aldosterone excretion, following logarithmic transformation, was highly significant ( $r$ $=0.840, P<0.001$ ). The response of the renin-angiotensin system to dietary sodium intake was reflected in changes of urinary sodium excretion (Fig. 3). There was a significant inverse correlation of both plasma renin activity and aldosterone excretion with 24-h urinary sodium excretion $(r=-0.768, r=-0.726$,

Table II. Hemodynamic Profile during Balanced Sodium Intake in Chronic Congestive Heart Failure

\begin{tabular}{|c|c|c|}
\hline & 10 meq sodium & 100 meq sodium \\
\hline Heart rate $(b p m)$ & $83 \pm 5$ & $88 \pm 4$ \\
\hline Mean arterial pressure $(\mathrm{mm} \mathrm{Hg})$ & $83 \pm 3^{*}$ & $88 \pm 4^{*}$ \\
\hline Right arterial pressure $(\mathrm{mm} \mathrm{Hg})$ & $6 \pm 2$ & $9 \pm 1$ \\
\hline $\begin{array}{l}\text { Pulmonary artery pressure } \\
\qquad(\mathrm{mm} \mathrm{Hg})\end{array}$ & $27 \pm 4^{*}$ & $36 \pm 3^{*}$ \\
\hline $\begin{array}{l}\text { Pulmonary wedge pressure } \\
\qquad(\mathrm{mm} \mathrm{Hg})\end{array}$ & $16 \pm 3^{*}$ & $24 \pm 1^{*}$ \\
\hline $\begin{array}{l}\text { Cardiac index (liter/min per } \\
M^{2} \text { ) }\end{array}$ & $2.13 \pm 0.10$ & $2.14 \pm 0.09$ \\
\hline Stroke volume index $\left(\mathrm{ml} / \mathrm{M}^{2}\right)$ & $26 \pm 2$ & $25 \pm 2$ \\
\hline $\begin{array}{l}\text { Systemic vascular resistance } \\
\left(\text { dyn } \cdot \mathrm{s} \cdot \mathrm{cm}^{-5}\right)\end{array}$ & $1,598 \pm 123$ & $1,610 \pm 130$ \\
\hline $\begin{array}{l}\text { Pulmonary vascular resistance } \\
\left(\text { dyn } \cdot \mathrm{s} \cdot \mathrm{cm}^{-5}\right)\end{array}$ & $453 \pm 88$ & $556 \pm 70$ \\
\hline
\end{tabular}

$* P<0.02$. All values mean \pm SEM.
Table III. Metabolic Response to Balanced Sodium Intake in Chronic Congestive Heart Failure

\begin{tabular}{lcc}
\hline & 10 meq Sodium & 100 meq Sodium \\
\hline Weight $(\mathrm{kg})$ & $76.5 \pm 5.0^{*}$ & $78.5 \pm 4.9^{*}$ \\
Plasma volume $(\mathrm{ml})$ & $3,025 \pm 242$ & $3,209 \pm 209$ \\
Total blood volume $(\mathrm{ml})$ & $5,062 \pm 430$ & $5,296 \pm 418$ \\
Creatinine clearance $(\mathrm{ml} / \mathrm{min})$ & $81 \pm 8$ & $82 \pm 9$ \\
Sodium: intake $(\mathrm{meq})$ & $9 \pm 1 \ddagger$ & $115 \pm 5 \ddagger$ \\
$\quad$ excretion $(\mathrm{meq})$ & $11 \pm 3 \ddagger$ & $63 \pm 15 \ddagger$ \\
Potassium: intake $(\mathrm{meq})$ & $84 \pm 7$ & $84 \pm 8$ \\
$\quad$ excretion $(\mathrm{meq})$ & $56 \pm 8$ & $60 \pm 7$ \\
Water: intake $(\mathrm{ml})$ & $1,809 \pm 204$ & $2,005 \pm 172$ \\
$\quad$ excretion $(\mathrm{ml})$ & $1,194 \pm 87$ & $1,265 \pm 199$ \\
Plasma norepinephrine $(\mathrm{pg} / \mathrm{ml})$ & $519 \pm 54 \S$ & $455 \pm 69 \S$ \\
Hematocrit $(\%)$ & $40 \pm 2$ & $39 \pm 2$ \\
Serum sodium $(\mathrm{mmol} / \mathrm{liter})$ & $136 \pm 1$ & $138 \pm 1$ \\
Serum potassium $(\mathrm{mmol} / \mathrm{liter})$ & $4.6 \pm 0.1$ & $4.4 \pm 0.11$ \\
Serum chloride $(\mathrm{mmol} / \mathrm{liter})$ & $102 \pm 2$ & $104 \pm 1$ \\
Serum bicarbonate $(\mathrm{mmol} / \mathrm{liter})$ & $23 \pm 1$ & $21 \pm 2$ \\
Blood urea nitrogen $(\mathrm{mg} / \mathrm{dl})$ & $20 \pm 2$ & $16 \pm 2$ \\
Serum creatinine $(\mathrm{mg} / \mathrm{dl})$ & $1.2 \pm 0.05$ & $1.2 \pm 0.06$ \\
\end{tabular}

$* P<0.02$

$\ddagger P<0.001$. All values mean \pm SEM.

$\S P<0.01$.

respectively; both $P<0.005$ ). Thus, when urinary sodium intake and excretion were increased, there was a concurrent suppression of plasma renin activity and urinary aldosterone excretion.

Subgroups of sodium and water excretion. In Table III, there was a considerable range of urinary sodium excretion during the $100 \mathrm{meq}$ sodium diet $(63 \pm 15 \mathrm{meq} / 24 \mathrm{~h}$; range of 2 to 141 $\mathrm{meq} / 24 \mathrm{~h}$ ). To further characterize patterns of sodium excretion, we segregated patients into those who had achieved neutral sodium balance ( $\mathrm{UNaV}>80 \mathrm{meq} / 24 \mathrm{~h}, n=5$ ) and those patients who were avidly retaining sodium (UNaV $<80 \mathrm{meq} / 24 \mathrm{~h}, n$ $=5$ ). The key metabolic and hemodynamic characteristics for individual patients in these two subgroups are shown in Table I. Despite virtually identical sodium intake (114 \pm 9 vs. $117 \pm 7$ meq), patients who had achieved neutral balance had a urinary sodium excretion of $102 \pm 10 \mathrm{meq} / 24 \mathrm{~h}$, while those with avid sodium retention had a urinary sodium excretion of $24 \pm 10 \mathrm{meq} /$ $24 \mathrm{~h}(P<0.001)$. Water intake was comparable $(2,178 \pm 254$ vs. $1,833 \pm 232 \mathrm{ml}$ ), yet patients in neutral balance excreted $1,851 \pm 58$ $\mathrm{ml}$, whereas those with avid sodium retention excreted only $678 \pm 47 \mathrm{ml}(P<0.001)$. Thus, despite an allowance of $1 \mathrm{wk}$ to achieve balance with a 100 meq sodium intake, $50 \%$ of the patients in this study continued to avidly retain sodium and water. Differences in intravascular volume did not appear to explain the range of sodium and water excretion. There was no significant difference in plasma volume $(3,311 \pm 274$ vs. $3,107 \pm 145 \mathrm{ml})$ or total blood volume $(5,331 \pm 671$ vs. $5,227 \pm 542 \mathrm{ml})$. Mean values for creatinine clearance were $84 \pm 8$ vs. $79 \pm 17 \mathrm{ml} / \mathrm{min}$. There was a tendency for individuals in the sodium retaining group to have a lower creatinine clearance, and there was also a statistically significant difference in blood urea nitrogen $(12 \pm 1$ vs. $20 \pm 4 \mathrm{mg} /$ dl, $P<0.05$ ). However, there was a highly significant difference in supine plasma renin activity. Despite suppression of renin 
overall, compared to the $10 \mathrm{meq}$ diet, those patients in neutral sodium balance had a plasma renin activity of $0.4 \pm 0.1 \mathrm{ng} / \mathrm{ml}$ per $\mathrm{h}$ while those avidly retaining sodium had a plasma renin activity of $1.8 \pm 0.4 \mathrm{ng} / \mathrm{ml}$ per $\mathrm{h}(P<0.005)$. Although there was overall suppression of urinary aldosterone excretion for both subsets of patients when compared to the 10 meq sodium diet, there was a significant difference of urinary aldosterone when patients in neutral balance were compared with those in avid sodium retention $(6.4 \pm 1.9$ vs. $14 \pm 2.4 \mu \mathrm{g} / 24 \mathrm{~h}, P<0.03)$. The differences between the neutral sodium and sodium retaining subgroups did not alter the relationship of plasma renin activity and urinary aldosterone excretion to the 24-h urinary sodium excretion (Fig. 3). There was a close correlation between the extent of renin-angiotensin system activity and urinary sodium excretion, irrespective of the tendency to achieve neutral balance, or retain sodium during the 100 meq sodium diet. The different patterns of sodium excretion were not a function of differences in systemic hemodynamics, as there were no significant differences of mean arterial pressure, pulmonary capillary wedge pressure, cardiac index, or systemic vascular resistance for the two subgroups of patients (Table I).

The influence and interactions of dietary sodium, renin system inhibition, and posture on the hemodynamic and hormonal profile of congestive heart failure. The influence and interactions of dietary sodium, renin system inhibition, and posture are shown as mean values in Figs. 4 and 5. These same data are presented in the Appendix (Fig. 7), where individual patient responses are identified.

The effect of dietary sodium manipulation on the hemodynamic profile of these patients with congestive heart failure was manifest by significant differences in mean arterial pressure, pulmonary artery pressure, and pulmonary wedge pressure (Fig. 4; see also Table II). All three pressures were lower on the 10 meq diet, when compared to the 100 meq sodium diet. The 10 meq sodium diet was also associated with activation of the reninangiotensin system, as assessed by both plasma renin activity and urinary aldosterone excretion (Fig. 5; see also Figs. 2 and 3). There was also a significantly higher plasma norepinephrine concentration during the 10 meq diet (Fig. 5; see also Table III).

Renin system inhibition with captopril resulted in significant differences of mean arterial pressure, pulmonary wedge pressure, and systemic vascular resistance. During the $10 \mathrm{meq}$ sodium diet, in the supine position, mean arterial pressure decreased from $83 \pm 3$ to $75 \pm 5 \mathrm{~mm} \mathrm{Hg}$ following captopril. There was a significant sodium-captopril interaction effecting mean arterial pressure $(P<0.02)$. Pulmonary wedge pressure decreased from $16 \pm 3$ to $13 \pm 2 \mathrm{~mm} \mathrm{Hg}$, and systemic vascular resistance decreased from $1,598 \pm 123$ to $1,348 \pm 92 \mathrm{dyne} \cdot \mathrm{s} \cdot \mathrm{cm}^{-5}$. There was no significant effect of captopril on heart rate, or cardiac index. The hemodynamic effects of captopril were paralleled in the head up tilt position as well as the supine position. Overall, there was little effect of captopril on systemic hemodynamics during the 100 meq sodium diet, with no significant differences in either the supine or tilt positions. Captopril had a significant effect on plasma renin activity (Fig. $5, P<0.02$ ). During the $10 \mathrm{meq}$ sodium diet, captopril resulted in an increase of supine plasma renin activity from $6.8 \pm 1.7$ to $46 \pm 16 \mathrm{ng} / \mathrm{ml}$ per $\mathrm{h}$. During the 100 meq sodium diet, captopril resulted in an increase of plasma renin activity from $1.1 \pm 0.3$ to $1.8 \pm 0.7 \mathrm{ng} / \mathrm{ml}$ per $\mathrm{h}$. The captopril-induced changes in plasma renin activity in the head up tilt position paralleled the changes evoked by captopril in the supine position. There was a significant sodium-captopril interaction effecting plasma renin activity $(P<0.04)$. Captopril did not result in significant changes in plasma norepinephrine.

Head up tilt did not result in significant heart rate changes, but there was a significant reduction of pulmonary wedge pressure $(P<0.001)$, and cardiac index $(P<0.02)$. While mean arterial pressure tended to decrease during head up tilt, particularly during the 10 meq sodium intake after treatment with captopril, tilt did not result overall in a significant decrease of mean arterial pressure. This was most likely a result of a baroreceptor-mediated increase of systemic vascular resistance, as the effect of head up tilt on the latter parameter was statistically significant $(P<0.005)$. However, individual patient responses varied. The difference between those patients who maintained their blood pressure during head up tilt versus those who experienced orthostatic hypotension is summarized in Fig. 7. During the 100 meq sodium diet, 2 of 10 patients had orthostatic hypotension due to no change, or decrease of systemic vascular resistance. Following captopril, 3 of 10 patients had orthostatic hypotension following captopril. The incidence of orthostatic hypotension was greater during the 10 meq sodium diet. 4 of the 10 patients had an orthostatic reduction in blood pressure, with three demonstrating a decrease in systemic vascular resistance and one increasing resistance, but to a level insufficient to maintain blood pressure. Following captopril, 6 of the 10 patients experienced orthostatic hypotension, with insufficient increase of systemic vascular resistance to maintain blood pressure. In the latter group of six patients, orthostatic hypotension was severe, with mean arterial pressure reaching values of $40-50 \mathrm{~mm}$ $\mathrm{Hg}$ in four cases. While an increase of heart rate would have been anticipated in the presence of orthostatic hypotension, heart rate actually decreased in three of the six patients who experienced orthostatic hypotension. Head up tilt did not result in a significant effect on plasma renin activity for either diet. However, tilt was associated with a significant effect on plasma norepinephrine $(P<0.02)$. Patterns or subgroups of hormonal response were not observed that could delineate differences for patients with or without orthostatic hypotension.

Dietary sodium, captopril, and head up tilt resulted in a significant interaction in terms of the observed changes in pulmonary wedge pressure $(P<0.01)$. During the 10 meq sodium diet, following converting enzyme inhibition, the lowest mean value of pulmonary wedge pressure was observed in the head up tilt position $(6 \pm 2 \mathrm{~mm} \mathrm{Hg})$. Fig. 6 summarizes the relationship of pulmonary wedge pressure and mean arterial pressure observed in the study. Mean arterial pressure and pulmonary wedge pressure were relatively high during the 100 meq sodium diet. The lowest mean arterial pressure was observed during the 10 meq sodium diet, particularly postcaptopril, associated with the lowest pulmonary wedge pressure.

\section{Discussion}

There is limited data regarding the influence of sodium intake on the hemodynamic and metabolic parameters of congestive heart failure. In a canine model of congestive heart failure, Watkins and co-workers found a biphasic relationship of renin-angiotensin system activity and sodium excretion (19). Early in the course of congestive heart failure, the renin-angiotensin system was activated as a compensatory mechanism with reduction of urinary sodium excretion and an increase of weight. 1-2 wk 


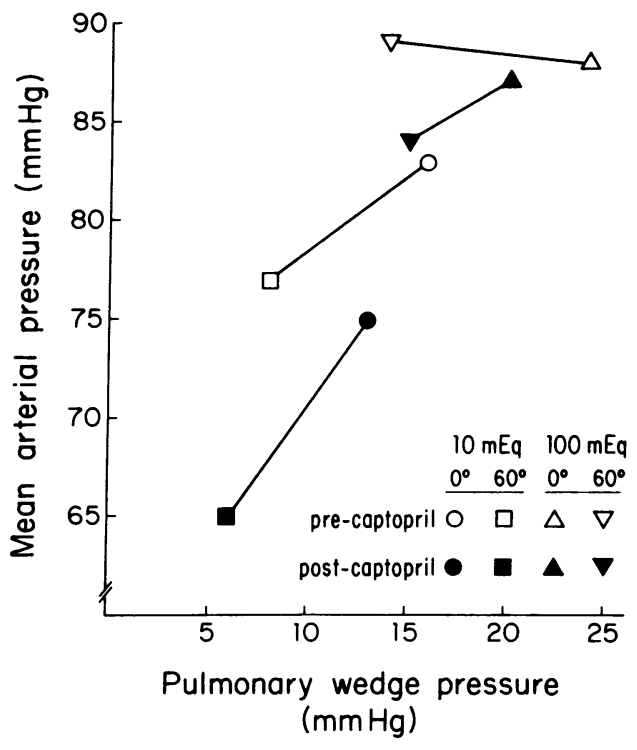

Figure 6. The relationship of pulmonary wedge pressure and mean arterial pressure for all stages of this study. The greatest reduction of mean arterial pressure occurred during the 10 meq sodium diet, particularly after administration of captopril, at which time pulmonary wedge is lowest. Each symbol represents the mean value for all 10 patients in this study. Fig. $7 \mathrm{~A}$ provides the individual patient responses.

following induction of congestive heart failure, the renin-angiotensin system was suppressed and urinary sodium excretion was increased. It was felt that angiotensin II was necessary to maintain blood pressure immediately following induction of heart failure, while plasma volume expansion later in the course of heart failure was the means by which mean arterial pressure was maintained so that angiotensin-mediated vasoconstriction was no longer necessary. There has likewise been limited clinical data during balanced sodium intake, that identifies mechanisms of sodium and water retention. Ayers and co-workers observed that sodium retention was virtually complete in heart failure, despite a relatively normal aldosterone secretion rate (1). Chonko and coworkers evaluated the role of the renin-angiotensin system in the sodium retention of edematous states, including congestive heart failure (2). Patients were loaded with varying amounts of sodium, but to a degree sufficient to result in edema. The degree to which the renin-angiotensin system was suppressed with sodium loading was not uniform and could not be explained. To date, there has not been a study that has attempted to assess the hemodynamic, metabolic, and neurohormonal interactions that occur during a structured sodium balance study where dietary sodium is manipulated, in patients who are not treated with diuretics. As such, the present study provides new information of these interactions.

Characteristics of congestive heart failure patients during 10 meq and 100 meq sodium intake. Comparing the two sodium diets, mean arterial pressure, pulmonary artery pressure, and pulmonary wedge pressure were significantly increased on the 100 meq sodium diet; right atrial pressure tended to increase, but this did not achieve statistical significance. There were no significant differences in heart rate, cardiac index, stroke volume index, systemic vascular resistance, or pulmonary vascular resistance. This indicates that the extent of vasoconstriction was unaltered by dietary sodium. Despite a 2-kg weight increase during sodium repletion, intravascular volume was not increased. It is possible that small changes occurred in ventricular volume or pressure, that were not detectable by the standard techniques which we employed. Such small changes in ventricular volume and pressure could conceivably result in increased ventricular stiffness, accounting for the increase in pulmonary wedge pressure and pulmonary artery pressure as well as the small increase in right atrial pressure. Such small changes would be difficult to quantitate. Alternatively, small changes in interstitial tissue fluid could alter venous compliance characteristics (20), or pulmonary parenchymal stiffness $(21)$, that could alter preload, reflected by right atrial and pulmonary wedge pressure. Therefore, the increase of sodium intake from 10 to $100 \mathrm{meq}$ was not translated into increased forward flow or intravascular volume. It is most likely that much of the retained sodium and water during sodium repletion was sequestered in the extravascular compartment. The small but significant increase of mean arterial pressure during the 100 meq sodium diet appeared more related to a small increment of systemic vascular resistance rather than changes in cardiac index or stroke volume index. In normal individuals, sodium loading can cause a small, but significant increase of blood pressure (22) and we cannot minimize the potential effects of this increase of mean arterial pressure in our patients with congestive heart failure. Small changes in perfusion pressure could influence the sensitivity to orthostatic hypotension, as observed in this study, and could also influence autoregulatory responses in target organs such as the kidney (23).

In congestive heart failure, the plasma norepinephrine concentration is increased $(24,25)$, but the response to dietary sodium has not been previously identified. Our study has identified that the plasma norepinephrine concentration is relatively higher in sodium-depleted heart failure patients, suggesting enhanced sympathetic nervous system activity. This observation parallels previous reports in normal subjects $(26,27)$. Using a sensitive microneurographic technique, a preliminary report by Leimbach and co-workers has demonstrated that the plasma norepinephrine concentration is a good index of sympathetic outflow (28). Taken together, these observations indicate that sympathetic outflow is greater in sodium-depleted vs. sodium-repleted heart failure patients.

The response of the renin-angiotensin system to dietary sodium manipulation parallels the observations in normal individuals where it is known that sodium depletion will result in activation of the renin-angiotensin system $(29,30)$. Significant differences in cardiac output or intravascular volume between the $10 \mathrm{meq}$ and $100 \mathrm{meq}$ sodium diets are not necessary to evoke changes in the degree to which the renin-angiotensin system is activated. Bartter and co-workers established that an increase in extracellular volume will result in suppression of the renin-angiotensin system independent of intracellular volume changes (31). Bull and co-workers have further shown that administration of sodium chloride will increase urinary sodium excretion and suppress the plasma renin and aldosterone secretion when intravascular blood volume is held constant, or is decreased by phlebotomy (32). We found a close correlation of plasma aldosterone with plasma renin activity for both sodium diets. This confirms the observations of Watkins and co-workers in dogs with congestive heart failure (19), and supports the hypothesis that the secretion of aldosterone in congestive heart failure is primarily regulated by plasma renin activity. For the 

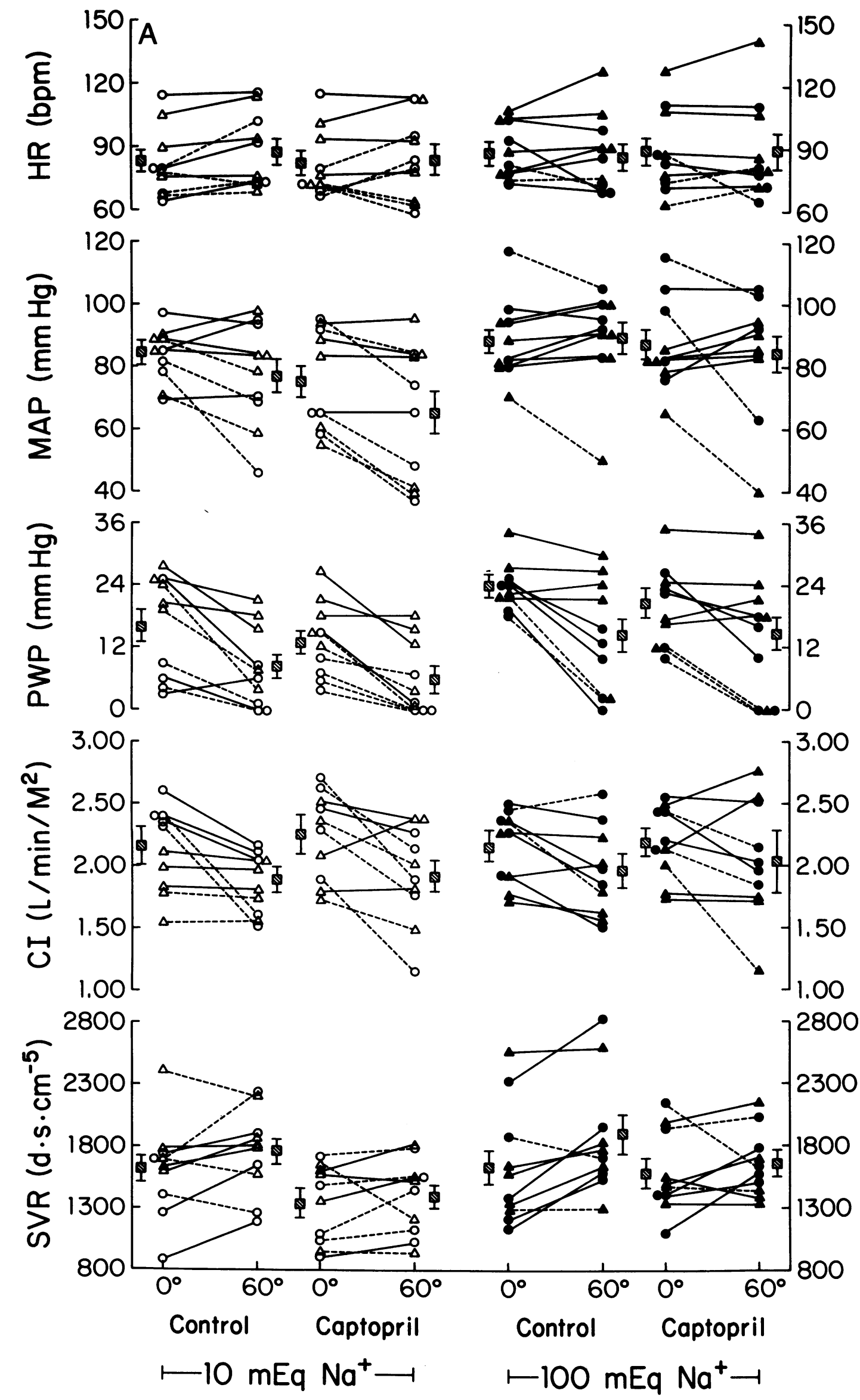

Figure 7 A. See Appendix for explanation. 

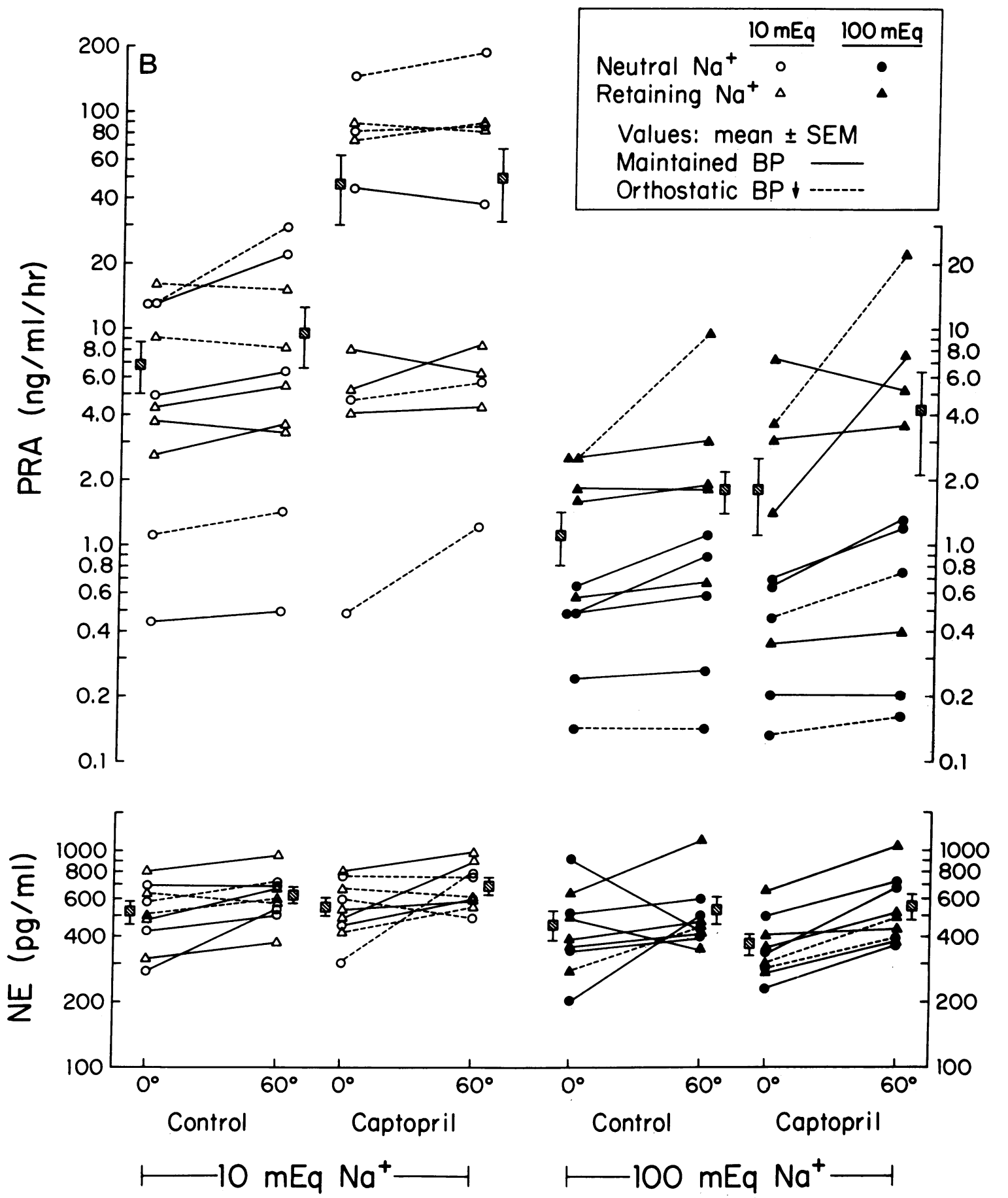

Figure 7 B. See Appendix for explanation.

10 meq sodium diet, and both the neutral sodium and retaining sodium subgroup responses to the $100 \mathrm{meq}$ sodium diet, there was a close correlation of urinary sodium excretion with both plasma renin activity and urinary aldosterone excretion. This finding underscores the importance of distal tubular sodium delivery to the macula densa as a major determinant for renin secretion. However, during the 100 meq sodium diet, one group of patients achieved neutral sodium balance with the greatest suppression of the renin-angiotensin system while the second group continued to avidly retain sodium so that the renin-angiotensin system was suppressed to a lesser degree.
Subgroup responses to sodium repletion. During the $100 \mathrm{meq}$ sodium intake, two patterns of response emerged. One group achieved neutral sodium balance, with daily sodium excretion commensurate with the 100 meq sodium diet. The second group of patients avidly retained sodium and water. There was no difference in blood volume for the two groups, suggesting that the retained sodium and water was sequestered in an extravascular site.

In normal individuals, increasing dietary sodium from 10 to $100 \mathrm{meq}$ will be reflected in urinary sodium excretion, with macula densa suppression of renin secretion (33). The present 
study, however, highlights a fundamental variation on this concept, in patients with congestive heart failure. While all patients demonstrated suppression of the renin-angiotensin system with the 100 meq sodium diet, there was a discrete and significant difference in plasma renin activity and urinary aldosterone excretion for the two subgroups during the 100 meq sodium diet. This difference was apparent for individual values as well as group mean values. The most likely explanation for the difference in sodium and water retention, and in renin system activation, is that those individuals retaining sodium continued to have increased proximal tubular sodium reabsorption, so that the dietary sodium load was not sensed by the macula densa. Therefore, the macula densa signal for renin secretion persisted, and perhaps the secretion of aldosterone actually perpetuated sodium and water retention in the distal tubule. Watkins and co-workers were able to demonstrate in their canine model of heart failure that dogs with a two-to threefold increase of plasma renin activity had as much sodium retention as animals where plasma renin activity was 10-20 times normal, suggesting that relatively small increases of renin and aldosterone could result in complete sodium retention. They concluded that moderate activation of the renin-angiotensin system was necessary for sodium and water retention, whereas markedly enhanced activation was necessary for a vasoconstrictor effect. Additional information is provided in the recent report of Dzau and Hollenberg (34). In patients with chronic congestive heart failure, treated with captopril, induction of natriuresis and correction of edema and hyponatremia could only be fully achieved with the addition of furosemide to captopril, thereby blocking tubular sodium reabsorption. The inability of patients with heart failure to excrete an oral sodium load was identified many years ago (35). At that time, however, a mechanism for this abnormality was not identified. Chonko and co-workers had previously observed two patterns of renin response during sodium loading in heart failure (2). In their patients, however, sodium retention was relatively uniform. While they did not measure hemodynamics, they felt that a hemodynamic effect, or "undefined factors," could result in fluid retention in those patients where renin and aldosterone were suppressed. In our study, we were able to demonstrate that a systemic hemodynamic mechanism could not distinguish patients who achieve neutral sodium balance from those who retained sodium. Mean arterial pressure and cardiac index were not significantly higher in the neutral sodium group so that hemodynamic differences could not account for the marked differences in urinary sodium excretion. We did not measure renal blood flow, and a comparison of glomerular filtration rate for the two subgroups did not reveal statistically significant differences. In the sodium-retaining group however, glomerular filtration rate was less than $50 \mathrm{ml} / \mathrm{min}$ in two of the five patients, so that we cannot totally exclude the contribution of a renal hemodynamic mechanism.

Vasoconstriction and sodium balance. Systemic vascular resistance was not significantly different when the 10 and $100 \mathrm{meq}$ sodium diets were compared, suggesting "fixed" vasoconstriction (36). Using only basal values, it would be difficult to determine whether vasoconstriction was fixed, or the result of different mechanisms of vasoconstriction in response to dietary sodium. However, important inferences can be drawn from the response to converting enzyme inhibition with captopril, which was administered as a single 25 -mg dose to acutely interrupt the reninangiotensin system. A significant reduction in systemic vascular resistance was induced by captopril during the 10 meq sodium diet, when the renin-angiotensin system was activated. However, there was virtually no reduction in systemic vascular resistance following one week of the 100 meq sodium diet, when the reninangiotensin system was suppressed. This indicated that vasoconstriction in the sodium-depleted state was mediated by angiotensin II, while in the sodium repleted state, vasoconstriction was not angiotensin-mediated. Thus, within the same patient population, we were able to identify that dietary sodium could alter the mechanism of vasoconstriction, while the absolute level of vasoconstriction (10 vs. 100 meq sodium) was constant. This observation in man is supported by the study of Watkins and co-workers (19). In their canine model, they observed that in the early stages of heart failure, when plasma renin activity was increased, administration of the teprotide converting enzyme inhibitor resulted in marked reduction of mean arterial pressure. As the duration of congestive heart failure progressed to the renin-independent phase, they could no longer elicit significant reductions of mean arterial pressure with teprotide. While vasoconstriction in the sodium-depleted state appears largely dependent on angiotensin II, the mechanism of vasoconstriction during sodium repletion was not identified in the present study, and would be open to speculation. However, vasoconstriction during the 100 meq sodium diet could not be specifically attributable to enhanced sympathetic nervous system activity, as the plasma norepinephrine concentration was actually lower in our patients during sodium repletion.

Sodium influence on the response to tilt. The assessment of the influence of sodium intake on the tilt response is a complex issue that may not be resolved by the findings in the present study. Nonetheless, several important issues can be addressed. In normal individuals, the gravitational stress of head up tilt is associated with peripheral pooling of blood, reduction of venous return, and subsequent reduction of cardiac output $(37,38)$. To protect and maintain blood pressure, head up tilt stimulates baroreceptor mechanisms that result in an increase of heart rate and systemic vascular resistance. The hormonal adjustment to gravitational stress includes a two- to threefold increase of plasma renin activity (39) and a comparable increase of plasma norepinephrine (26). There is evidence that the response to tilt can be influenced by sodium intake in normal individuals. Sancho and co-workers have shown a greater tendency for orthostatic hypotension in the sodium-depleted state (29). Vascular adaptation to head up tilt is more dependent on the renin-angiotensin system, as induction of orthostatic hypotension to the expression of syncope could be evoked following converting enzyme inhibition.

The complexity of the tilt response in congestive heart failure is based on several observations. First, Abelmann and co-workers have demonstrated what they termed an increased tolerance to orthostatic stress in heart failure (40). This was due to the fact that the anticipated decrease of cardiac output during head up tilt did not occur. The most likely explanation for this observation was massive peripheral edema, and increased venous compliance that was independent of position. Second, patients with congestive heart failure have an impaired response to many autonomic stimuli. This includes a blunting of heart rate and resistance changes to tilt $(7,8,41)$, blunting of hormonal responses to tilt (8), and abnormal responses to cold pressor testing, and the Valsalva maneuver (7). The complexity of the tilt response in heart failure is compounded by the fact that there may be subgroups of responses to tilt. In a study of 41 patients (8), we found that roughly half of our patients had a response similar to that ob- 
served by Abelmann. However, the remainder of the patients demonstrated a relatively intact afferent stimulus of decreased cardiac output during venous pooling. In the latter group, however, two-thirds of patients were able to maintain their blood pressure, while one-third experienced orthostatic hypotension in a manner analogous to patients with idiopathic orthostatic hypotension (42).

In the present study, the response to tilt was qualitatively different for the two sodium diets. In the sodium-repleted state, 2 of the 10 patients experienced an orthostatic reduction of blood pressure, due to no change, or a decrease of systemic vascular resistance. Following captopril, a third patient also demonstrated orthostatic hypotension, most likely due to the withdrawal of the vasoconstrictive influences of angiotensin II. The absence of a significant increase of heart rate during tilt may have reflected the abnormal autonomic responsiveness that characterizes heart failure. In the sodium-depleted state, four patients had an orthostatic reduction in blood pressure with three demonstrating an actual decrease of systemic vascular resistance and one patient increasing systemic vascular resistance but to a level insufficient to avert blood pressure reduction. Following converting enzyme inhibition, 6 of the 10 patients experienced orthostatic hypotension with insufficient increase of systemic vascular resistance. The anticipated increase of heart rate was again not observed. It is likely that the underlying autonomic abnormalities in congestive heart failure contributed to this inappropriate response, yet sympathetic nervous system activity was actually greater during the 10 meq sodium diet, as plasma norepinephrine concentrations were increased. One possible explanation for the difference of the tilt response for the two diets may be that increased interstitial tissue pressure and turgor is important in the sodium-repleted state, providing additional vascular stiffness to avert orthostasis (20). Increased interstitial tissue pressure could prevent augmentation of venous capacitance, and the subsequent venous pooling of blood that is normally observed during gravitational stress. A study by Magrini and Niarchos (43) supports this hypothesis. In a group of patients with massive peripheral edema, the normal hemodynamic response to head up was blunted. However, following diuretic therapy and marked reduction of peripheral edema, they found that venous pooling of blood and reduction of central blood volume resulted in a response more typical of normal individuals. An additional explanation or factor may be the contribution of cardiac filling pressures. We found an association between pulmonary wedge pressure and mean arterial pressure, with the greatest reduction of blood pressure occurring in those patients with the lowest pulmonary wedge pressure. In a previous study of diuretic-treated patients, we observed that the rapid infusion of normal saline into the central circulation could reverse or minimize the tendency for orthostatic hypotension by inducing small changes in cardiac filling pressures, without a significant increase of cardiac index or stroke volume index (44). Thus, the contribution of cardiac filling pressures to the maintenance of blood pressure during tilt may be more critical in congestive heart failure, when the ventricle is dilated, compared to normal individuals. In the present study, we have also observed a lack of appropriate hormonal increase during tilt, irrespective of dietary sodium intake or the occurrence of orthostatic hypotension. Plasma renin activity did not increase during tilt with either diet. While tilt resulted in an increase of norepinephrine, the magnitude of increased norepinephrine was not comparable to that observed in normal individuals during head up tilt (26), which is more strik- ing, when one considers the presence of orthostatic hypotension in many of our patients.

In summary, an increase of dietary sodium intake from 10 to 100 meq resulted in a 2-kg weight gain, suppression of the renin-angiotensin system, and a decrease of sympathetic nervous system activity, in patients with chronic congestive heart failure. The absence of significant increase in blood volume or cardiac output during this weight gain was compatible with an extravascular sequestration of sodium and water. There were two subgroups of response to sodium loading: a group of patients who achieved neutral balance, and a group of patients who continued to avidly retain sodium and water. While this difference could be influenced by an undefined hormonal mechanism, or subtle differences in renal function, it was not due to differences in cardiac function. Vasoconstriction in the sodium-depleted state was mediated by the renin-angiotensin system, but vasoconstriction during sodium repletion was independent of the renin-angiotensin system, and did not respond to converting enzyme inhibition. Sodium depletion was also accompanied by a greater expression of inadequate circulatory compensation to gravitational stress. This was characterized by a greater occurrence of orthostatic hypotension both before and after blockade of angiotensin-mediated vasoconstriction. The marked increase of renin following converting enzyme inhibition in the sodiumdepleted state, and the suppression of renin secretion during sodium repletion, indicated a retained relative sensitivity of the macula densa signal for renin secretion. In contrast, the cardiopulmonary mechanoreceptor stimulus for renin secretion during tilt was blunted, despite evidence of increased sympathetic nervous system activity.

\section{Appendix}

Individual hemodynamic and hormonal patient responses to dietary sodium manipulation, head up tilt, and converting enzyme inhibition with captopril are shown in Fig. 7. Data for the 10 meq sodium diet are given in the two columns on the left, and that of the 100 meq sodium diet are given in the two columns on the right, for each variable. Within each column, supine values are indicated by $0^{\circ}$ and the head up tilt values are indicated by $60^{\circ}$. The precaptopril data is indicated by "control," and the response to the $25-\mathrm{mg}$ oral dose of captopril is indicated by "captopril." Solid lines connecting the supine and tilt data points indicate those individuals who maintained their blood pressure during head up tilt, and the broken lines indicate those individuals who experienced orthostatic hypotension during head up tilt. To identify the individuals who achieved neutral balance versus those who avidly retained sodium in response to the 100 meq sodium diet, two different sets of symbols are used, that are consistent with the symbols used for all the figures. The circles represent those individuals who achieved neutral balance, and triangles indicate those individuals who were avidly retaining sodium. For consistency, the symbols are also indicated for the $10 \mathrm{meq}$ sodium diet. In addition to the individual patient data points, mean values are indicated by the hatched squares, along with the standard error of the mean. The mean values of Fig. 7, and the statistical results of the twoway analysis of variance for these individual patients, are given in the text as Fig. 4 and Fig. 5.

\section{Acknowledgments}

The statistical assistance of J. Most and B. Walter is gratefully acknowledged.

This study was supported in part by General Clinical Research Grant RR-47 from the National Institutes of Health. Dr. Cody is an Established Fellow of the New York Heart Association. 


\section{References}

1. Ayers, C. R., R. E. Bowden, and J. P. Schrank. 1972. Mechanisms of sodium retention in congestive heart failure. Adv. Exp. Med. Biol. 17: 227-243.

2. Chonko, A. M., W. H. Bay, J. H. Stein, and T. F. Ferris. 1977. The role of renin and aldosterone in salt retention of edema. Am. J. Med. 63:881-889.

3. Ikram, H., W. Chan, E. A. Espiner, and M. G. Nicholls. 1980. Haemodynamic and hormone response to acute and chronic furosemide therapy in congestive heart failure. Clin. Sci. Mol. Med. 59:443-449.

4. Cody, R. J., and J. H. Laragh. 1983. The role of the renin-angiotensin aldosterone system in the pathophysiology of chronic heart failure. In Drug Treatment of Heart Failure. J. Cohn, editor. Advanced Therapeutic Communications, Inc./Yorke Medical Books, New York. 3551.

5. Francis, G. S., S. R. Goldsmith, B. Levine, M. T. Olivari, and J. N. Cohn. 1984. The neurohormonal axis in congestive heart failure. Ann. Intern. Med. 101:370-377.

6. Hamilton, R. W., and V. M. Buckalew, Jr. 1984. Sodium, water, and congestive heart failure. Ann. Intern. Med. 100:902-903.

7. Cody, R. J., K. W. Franklin, J. Kluger, and J. H. Laragh. 1982. Mechanisms governing the postural response, and baroreceptor abnormalities in chronic congestive heart failure: effects of acute and longterm converting enzyme inhibition. Circulation. 66:135-141.

8. Kubo, S. H., and R. J. Cody. 1983. Circulatory autoregulation in chronic congestive heart failure. Response to tilt in 41 patients. $\mathrm{Am} . \mathrm{J}$. Cardiol. 52:512-518.

9. Rushmer, R. F. 1976. Cardiovascular Dynamics. W. B. Saunders Company, Philadelphia. 217-220.

10. Cody, R. J., and J. H. Laragh. 1982. Use of captopril to estimate renin-angiotensin-aldosterone activity in the pathophysiology of chronic heart failure. Am. Heart J. 104:1184-1189.

11. Cody, R. J., G. L. Schaer, A. B. Covit, K. Pondolfino, and G. William. 1982. Captopril kinetics in chronic congestive heart failure. Clin. Pharmacol. Ther. 32:721-726.

12. Grossman, W., and L. P. McLaurin. 1980. Clinical measurement of vascular resistance and assessment of vasodilator therapy. In Cardiac Catheterization and Angiography. W. Grossman, editor. Lea \& Febiger, Philadelphia. 116-23.

13. Preibisz, J. J., J. E. Sealey, R. M. Aceto, and J. H. Laragh. 1982. Plasma renin activity measurements: an update. Cardio. Rev. Rep. 5: 787-804.

14. Peuler, J. D., and G. A. Johnson. 1977. Simultaneous single isotope radioenzymatic assay of plasma norepinephrine, epinephrine, and dopamine. Life Sci. 21:625-636.

15. Feldschuh, J., and Y. Enson. 1977. Prediction of the normal blood volume. Relation of blood volume to body habitus. Circulation. 56:605-612.

16. Sealey, J. E., F. R. Bühler, J. H. Laragh, E. L. Manning, and H. R. Brunner. 1972. Aldosterone excretion. Physiological variations in man measured by radioimmunoassay or double-isotope dilution. Circ. Res. 31:367-378.

17. Wallenstein, S., C. L. Zucker, and J. L. Fleiss. 1980. Some statistical methods useful in circulation research. Circ. Res. 47:1-9.

18. Kleinbaum, D. G., and L. L. Kuper. 1978. Applied Regression Analysis and Other Multivariable Methods. Duxbury Press, North Scituate. $180-187$.

19. Watkins, L., Jr., J. A. Burton, E. Haber, J. R. Cant, F. W. Smith, and A. C. Barger. 1976. The renin-angiotensin-aldosterone system in congestive heart failure in conscious dogs. J. Clin. Invest. 57:1606-1617.

20. Zelis, R., S. F. Flaim, A. J. Liedtke, and S. H. Nellis. 1981. Cardiocirculatory dynamics in the normal and failing heart. Ann. Rev. Physiol. 43:455-476.

21. Fishman, A. P. 1972. Pulmonary edema. The water-exchanging function of the lung. Circulation. 46:390-408.

22. Parfrey, P. S., P. Wright, F. H. Goodwin, M. H. Vandenburg, J. M. P. Holly, S. J. W. Evans, and J. M. Ledingham. 1981. Blood pressure and hormonal changes following alteration in dietary sodium and potassium in mild essential hypertension. Lancet. 1:59-63.
23. Hollenberg, N. K. 1979. The physiology of renal circulation. In Renal Disease. 4th ed. D. A. K. Black, editor. Oxford University Press, London. 30-63.

24. Thomas, J. A., and B. H. Marks. 1978. Plasma norepinephrine in congestive heart failure. Am. J. Cardiol. 41:233-343.

25. Cody, R. J., K. W. Franklin, J. Kluger, and J. H. Laragh. 1982. Sympathetic responsiveness and plasma norepinephrine during therapy of chronic congestive heart failure with captopril. Am. J. Med. 72:791797.

26. Lilavivathana, U., and R. G. Campbell. 1980. The influence of sodium restriction on orthostatic sympathetic nervous activity. Arch. Intern. Med. 1485-1489.

27. Watson, R. D., M. D. Esler, P. Leonard, and P. I. Korner. 1984. Influence of variation in dietary sodium intake on biochemical indices of sympathetic activity in normal man. Clin. Exp. Pharmacol. Physiol. 11:167-170.

28. Leimbach, W. N., Jr., P. E. Aylward, and A. L. Mark. 1985. Correlations of plasma norepinephrine levels and direct measurements of sympathetic nerve activity in patients with heart failure. Circulation. 72:III-246. (Abstr.)

29. Sancho, J., R. Re, J. Burton, A. C. Barger, and E. Haber. 1976. The role of the renin-angiotensin-aldosterone system in cardiovascular homeostasis in normal human subjects. Circulation. 53:400-405.

30. Millar, J. A., B. P. McGrath, P. G. Matthews, and C. I. Johnston. 1981. Acute effects of captopril on blood pressure and circulatory hormone levels in salt-replete and depleted normal subjects and essential hypertensive patients. Clin. Sci. (Lond.). 61:75-83.

31. Bartter, F. C., G. W. Liddle, L. E. Duncan, Jr., J. K. Barber, and C. Delea. 1956. The regulation of aldosterone secretion in man: the role of fluid volume. J. Clin. Invest. 35:1306-1315.

32. Bull, M. B., R. S. Hillman, P. J. Cannon, and J. H. Laragh. 1970. Renin and aldosterone secretion in man as influenced by changes in electrolyte balance and blood volume. Circ. Res. 27:953-960.

33. Laragh, J. H., and J. E. Sealey. 1973. The renin-angiotensinaldosterone hormonal system and regulation of sodium, potassium and blood pressure homeostasis. In Handbook of Physiology, Section 8: Renal Physiology. J. Orloff and R. W. Berliner, editors. Williams \& Wilkins Press, Baltimore. 831-908.

34. Dzau, V. J., and N. K. Hollenberg. 1984. Renal response to captopril in severe heart failure: role of furosemide in natriuresis and reversal of hyponatremia. Ann. Intern. Med. 100:777-782.

35. Braunwald, E., W. H. Plauth, Jr., and A. G. Morrow. 1965. A method for the detection and quantification of impaired sodium excretion. Circulation. 32:223-231.

36. Bartter, F. C. 1964. Cardiac failure and hormonal control of fluid and electrolyte balance. Surg. Gynecol. Obst. 118:767-777.

37. Molzahn, M., T. Dissmann, S. Halim, F. W. Lohmann, and W. Oelkers. Orthostatic changes of haemodynamics, renal function, plasma catecholamines and plasma renin concentration in normal and hypertensive man. Clin. Sci. (Lond.). 42:209-222.

38. Tuckman, J., and J. Shillingford. 1965. Effect of different degrees of tilt on cardiac output, heart rate, and blood pressure in normal man. Br. Heart J. 28:32-39.

39. Oparil, S., C. Vassoux, C. A. Sanders, and E. Haber. 1970. Role of renin in acute postural homeostasis. Circulation. 41:89-96.

40. Abelmann, W. H., and K. Farreduddin. 1969. Increased tolerance of orthostatic stress in patients with heart disease. Am. J. Cardiol. 23: 354-363.

41. Levine, T. B., G. S. Francis, S. R. Goldsmith, and J. N. Cohn. 1983. The neurohumoral and hemodynamic response to orthostatic tilt in patients with congestive heart failure. Circulation. 67:1070-1075.

42. Ibrahim, M. M., R. C. Tarazi, H. P. Dustan, and E. L. Bravo. 1974. Idiopathic orthostatic hypotension: circulatory dynamics in chronic autonomic insufficiency. Am. J. Cardiol. 34:288-294.

43. Magrini, F., and A. P. Niarchos. 1983. Hemodynamic effects of massive peripheral edema. Am. Heart J. 105:90-97.

44. Cody, R. J., K. W. Franklin, and J. H. Laragh. 1982. Postural hypotension during tilt with chronic captopril and diuretic therapy of severe congestive heart failure. Am. Heart J. 103:480-484. 